\title{
TECHNOLOGY STATUS REPORT: OFF-GAS TREATMENT TECHNOLOGIES FOR CHLORINATED VOLATILE ORGANIC COMPOUND AIR EMISSIONS (U)
}

by

J. Rossabi and J. S. Haselow

Westinghouse Savannah River Company

Savannah River Site

Aiken, South Carolina 29808

Technical deliverable being deposited at OSTI.

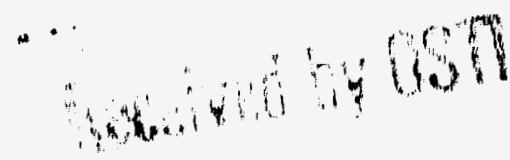

This report was prepared in connection with work done under Contract No. DE-ACO9-89SR18035 with the U.S. Department of Energy. By acceptance of this report, the publisher and/or recipient acknowledges the U.S. Govemment's right to retain a nonexclusive, royalty free license in and to any copyright covering this report, along with the right to reproduce and to authorize others to reproduce all or part of the copyrighted report. 


\section{DISCLAIMER}

This report was prepared as an account of work sponsored by an agency of the United States Government. Neither the United States Government nor any agency thereof, nor any of their employees, makes any warranty, express or implied, or assumes any legal liability or responsibility for the accuracy, completeness, or usefulness of any information, apparatus, product, or process disclosed, or represents that its use would not infringe privately owned rights. Reference herein to any specific commercial product, process, or service by trade name, trademark, manufacturer, or otherwise does not necessarily constitute or imply its endorsement, recornmendation, or favoring by the United States Government or any agency thereof. The views and opinions of authors expressed herein do not necessarily state or reflect those of the United States Government or any agency thereof.

This report has been reproduced directly from the best available copy.

Available to DOE and DOE contractors from the Office of Scientific and Technical Information, P.O. Box 62, Oak Ridge, TN 37831; prices available from (615; 576.8401, FTS 626-8401.

Available to the public from the National Technical Information Service, U.S. Department of Commere, 5285 Port Royal Rd., Springfield, VA. 22161. 


\section{INTRODUCTION AND ORJECTIVES}

The purpose of this document is to revicw technologies for treatment of air streams that contain chlorinated volatile organic compounds (CVOCs) and to describe a Department of Energy Office of Technology Development program that is planned to demonstrate innovative technologies for the abatement of CVOC emissions. This report describes the first phase of testing of off-gas treatment technologies. At least one more phase of testing is planned. Guidance for the preparation of this document was provided by a predecisional draft outline issued by the Department of Energy's Office of Technology Development.

The report is intended to evaluate the technical and regulatory aspects, public acceptance, and estimated costs of technologies selected for development and testing. These technologies are compared to currently practiced or baseline methods for treatment of CVOC-laden airstreams. A brief overview is provided rather than detailed cost and data comparisons because many of these technologies have not yet been field tested. A description of other promising technologies for the treatment of CVOC emissions is also included.

Trichloroethylene (TCE) and perchloroethylene (PCE) were used for industrial cleaning and solvent applications for several decades. These chemicals can be classified as CVOCs. As a result of past standard disposal practices, these types of compounds are persistent groundwater and soil contaminarnts throughout the United States and the Department of Energy Complex. The currently preferred technology for remediating or containing these contaminants is to recover the contaminated groundwater, strip it with air, and then treat or discharge the resulting air stream. CVOC contamination of soils in the vadose zone can be removed by soil venting. In this case the CVOC is removed in the gas or air phase directly and stripping is not required. As the 1990 Clean Air Act Amendments are implemented, the allowable discharges of CVOCs will be significantly reduced. Due co these increased regulatory standards, an improvement in reduction methods would result in a sigrificant cost savings.

Based on their stage of development, technologies for abatement of CVOC emissions can be grouped into three categories: existing technologies, cmerging technologies, and evolving techrologies. The existing, technologies are those that are currently practiced. Energing technologies are those that are ready or ncarly ready for testing at the application or ficld scale, but do not have a proven history of success outside the laboratory. Therefore, it is difficult to compare emerging technologies with existing technologies. The evolving technologies are those that are technically sound, but are being researched and developed at a smaller scale than the emerging technologies.

\section{EXISTING TECHNOLOGIES}

The currently existing baseline technologies for abating CVOC emissions are: activated carbon adsorption, incineration, and catalytic destruction (Rinko and Traester, 1988; Buck and Scider, 1\%)1; Adams and Clark. $1(x) 1)$.

\section{Activated Carbon Adsorption}

Activated carbon adsorption is a simple, effective process where CVOCs are adsorbed to the carbon as the contaminated gas stream contacts it. The percent removal of a contaminant depends on that contaminant's carbon adsorption isotherm (Speth and Miltner, 1990). The drawback of this process is that it is a transfer of CVOC from one phase to anocher without any destruction. Although processes for regenerating the carbon and destroying the adsorbed CVOC exist, these are often costly and may represent more than 50 percent of the cost of the system (Oxenford and Lykins, 1991). The established method for regeneration of the activated carbon is by thermal processes such as inlrared heating, incineration or catalysis (Koffskey and Lykins, 1990; Adams and Clark, 1991). Other regeneration methods have recently been developed that have the potential to make the carbon adsorption process less expensive to operate. Methods considered emerging technologies include steam reforming (Adams and Clark, 1991; Sprung, personal communication, 1991), and bioreaction (Choxick and Irvine, 1991). Microwave regeneration ('Varma et al., 1987; Varma and 
Nandi, 1991) is an evolving technology that shows potential for the effective and efficient recycling of carbon. An additional option for carbon regeneration is to desorb the CVOC with an inert gas (Varma et al., 1987) and then condense the CVOC for recycling. Recycling by volatilization followed by condensation has been successfully used to recover chlorofluorocarbons (Basta, 1991). These emerging and cvolving technologies must be validatec by full scale demonstrations.

\section{Incineration}

Incineration, or high-temperature oxidation is a simple technology best suited for streams wilth high concentrations of CVOC's. Compared to existing activated carbon adsorption methods, incineration has greater initial capital costs but lower operating costs. The incineration of CVOC's requires a fuel source. Incineration can have relatively high energy demands depending upon the concentration of CVOC's in the waste stream. Total costs for incineration are approximately $\$ 2$ to $\$ 6$ per kilogram of CVOC versus approximately $\$ 15$ per $\mathrm{kg}$ for adsorption, and destruction efficiencies of greater than 99.9 percent can be routinely achieved. Incineration of CVOC's can produce chlorinated products of incomplete combustion such as dioxin, as well as hydrochloric acid and nitrogen oxides. However, the relcase of these by-products has been successfully controlled in bench scale studies using ammonia injection (Takacs and Moilanen, 1991). One of the main barriers in the use of incinerators for treating waste is public objection. Despite the large amount of technical data available indicating the advantages of incineration over many other methods with respect to destruction efficiency, safety, and cost, the general public adheres to a "not in my backyard" position when a site selection process is initiated. This position is strengthened by the public's increased awareness of environmental issues and some highly publicized environmental catastrophes (Steverson, 1991).

\section{Catalytic Destruction}

Catalytic destruction has recently emerged as an abatement method for CVOC emissions. This prosess has lower energy dernands than incineration and is better suited for waste streams that have relatively low concentrations of CVOCs (Palazzolo et al., 1986; Herbert, 1990; Frost et al., 1991). Destruction efficiencies of 90 to $95 \%$ have been achieved, however, this process normally requires frequent recycling or regeneration of the catalyst. This is due to the permanent deactivation of the commonly employed, noble, metal catalyst that is known to occur because of the presence of process-formed chlorides (Kittrell et al, 1991). A proprietary base metal catalyst has recently been tested by its manufacturer and was found to avoid the deactivation problems of the noble metal catalyst and yet it maintains a high conversion efficiency (Kiltrell et al, 1991). The performance of this catalyst should be confirmed by independent tests. As with incinerition, further treatment of the off-streams from the calalytic process may be needed to remove or neutralize hydrochloric acid. Additionally, this technology requires a fuel or electrical heat source. Costs for the reduction of CVOCs with catalytic process are comparable to incineration.

\section{EMERGING 'TECHNOLOGIES}

Because of the anticipated wide-spread need for the abatement of CVOC emissions, a small reduction in the cost of CVOC removal would result in a tremendous savings for the Department of Encrgy and United States industry. The greatest overall cost savings would be in reduced operating costs, but simplification of the CVOC treatment process could result in reduced capital and start-up costs. As a result, improved technologies for CVOC removal are being aggressively developed and pursued. A description of technologies that are being considered for Phase I of the off-gas treatment demonstration is provided below.

\section{Gas-Phase Membrane Separation}

Gas-phase membrane separation is a mature technology where gas-phase components are selectively separated as they flow through a specially designed proprietary membrane (Wijmans et al., 1990). The estimated operating costs for this technology are about $\$ 6$ per $\mathrm{kg}$ of CVCC recovered. One of the advantages of the process is that the removed TCE and PCE can be recycled. A company that will take the

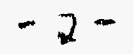


TCE/PCE from the demonstration of this technology has been identified. The disadvantage is that the current technology is more expensive than existing technologies. The main reason for the relatively high cost is that currently available membranes can only remove a portion of the TCE or PCE from the waste stream per cycle thereby requiring multiple cycles.

The principal investigators for this project are Craig King and Mike Schleibe of Westinghouse Hanford Company, and the industrial partner and developer of the process is J.G. Wijmans of Membrane Technology \& Research Inc. Safety-Kleen will recycle the solvent.

\section{Gas-Phase Bioreaction}

A gas-phase bioreactor will be used to aerobically break down CVOCs to carbon dioxide, water and chloride ions. The reactor will use a packed bed consisting of ceramic beads on which a biofilm will be maintained. Indigenous organisms capable of co-metabolizing TCE will be developed. The advantage of this system is that the operating costs are minimal and no hazardous byproducts are produced. The disadvantages include maintaining a viable biofilm and the requirement of long residence times. Work. on similar technology has been done in the treatment of grouridwater contaminated with TCE (Strandberg et al., 1989). Envirogen Corporation has successfully treated vapor phase concentrations of TCE in the laboratory with $90 \%$ destruction efficiency.

The principal investigat or for this project is Christopher Berry of the Savannah River Technology Center and the industrial partners are Envirogen Corporation and ECOVA Corporation.

\section{Carbon Regeneration by Stcam Reforming}

TCE and PCE are removed from a gas stream by adsorption on granular activated carbon and are later desorbed by passing $260^{\circ} \mathrm{C}$ steam over the activated carbon. The CVOC-laden steam is passed through a moving-bed reactor, that is packed with ceramic spheres that are coated with a slurried base. In the reactor, which operates at $700^{\circ} \mathrm{C}$, the CVOCs are dechlorinated. The reactor ereates hydrochloric acid that is neutralized by the slurry base. The $\mathrm{HCl}$ depleted stream from the reactor is sent to a steam reforming reactor, which operates at $15 \% 0^{\circ} \mathrm{C}$, where all the undestroyed organic materials are completely mineralized to $\mathrm{CO}_{2}$ and $\mathrm{H}_{2} \mathrm{O}$. The advantages of this technolugy are: 1) the system is poriable, 2) the system is suited for 55 gallon drums of carbon, 3) operating costs are estimated to be about $\$ 1$ per $\mathrm{kg}$ of CVOC, 4) 99.99 percent destruction efficiencies have been achieved, and 5) all emissions from the system meet air quality standards. Disadvantages are that all of the $\mathrm{HCl}$ generated may not be reacted.

The principal investigator for this project is Jerry Sprung of Sandia National Laboratories and the industrial partner is Synthetica Technologies, Incorporated. This technology will also be tested at the Hanford Sitc on a carbon tetrachloride $\mathrm{CCl}_{4}$ as part of the Arid Site Intcgrated Demonstration.

\section{High-Energy Corona or Low-Energy Plasma}

This technology uses several nonconductive electrodes within a reactor to create a low-temperature plasma. The plasma is created as the electrodes discharge causing the gas within the reactor to partially ionize. In other words, the electrical field will force current to flow by stripping electrons off neutral gas molecules. The electrons discharged are highly reactive and catalyze the reaction of TCE and PCE. The advantages of this technology are that no heating, additives, or catalysts are required and the energy consumption is relatively low. The disadvantage is that it is unproven for treatment of high-llow rate streams required for field demonstration.

The principal investigator for this project is William Heath of Battelle Pacific Northwest Laboratory. There is currently no industrial partner. 
Photocatalytic Oxidation

Photocatalytic oxidation usually refers to the process in which a contaminant is oxidized by free radicals formed from the interaction of light and a catalyst such as ozone, hydrogen peroxide, or titanium dioxidc. The photocatalytic oxidation process typically uses an ultraviolet (UV) light source and one or a combination of the oxidizing agents listed above. For organic compounds such as TCE or PCE, the oxidation process is actually multifaceted. The contaminant can be destroyed by direct photolysis through the molecular absorption of UV light, inceraction of the contaminant with the oxidant, the oxidation of the contaminant by free radicals formed from direcl photolysis of the oxidant, or interaction of the two oxidants such as ozone and hydrogen peroxide (Glaze et al., 1987; Ollis et al., 1991). The production of free radicals has been found to be the most significant mechanism in these systems (Glaze et al., 1987; Peyton and Glaze, 1988; Glaze and Kang, 1989a; Glaze and Kang, 1989b). Most work in this area has been done using an aqueous waste stream; however, for surface site interactions such as titanium-dioxide mediated processes, a vapor phase waste stream should be mitigated at similar if not increased rates due to a lower concentration of radical scavengers. Some common scavengers in natural waters are inorganic carbon species and natural humic substances (Zafiriou, 1977; Fischer et al., 1987; Glaze and Kang, 1989b). The principal off-gas products are carbon dioxide, water, and hydrochloric acid. Complete mineralization has been achieved (Ollis et al., 1991) and is possible in practice dependent on the concentration of radical scavengers in the waste stream. Two advantages of this process are low capital costs and low operating costs while maintaining high destruction efficiencies. It is currently unproven technology at the field scale.

The principal investigator is Carol Eddy of Savannah River Technology Center and Universily of Wisconsin is the academic partner.

\section{EVOLVING AND EMERGING TECHNOLOGIES FOR FUTURE DEMONSTRATION}

Other technologies that are emerging or evolving for abatement of CVOC emissions are brichly described below. These technologies were not selected for this phase of the program, but may be tested as part of another phase of Off-Gas Treatment technology demonstrations under the SRS Integrated Demonstration.

\section{Carbon Regeneration by Bioreaction}

Activated carbon adsorption in conjunction with bioreaction is used to destroy CVOCs. This technology has had its seminal work accomplished in the water treatment field to eliminate bacteria and organic carbon (DeWaters and DiGiano, 1990; Servais et al., 1991; Chozick and Irvine, 1991). The process involves a surfacial biomass growth which can degrade organics on granular activated carbon. The large available surface area on the carbon ensures a high biomass to organic carbon ratio allowing for efficient degradation. This technology is similar to the gas-phase bioreaction described above but may incorporate the added benefits of carbon adsorption and increased surface area to support growth. This process is in the research and development stage.

Current known principal investigators are Daniel Smith at lowa State University and Colin Felton at the University of Cincinnati.

\section{Bremsstrahlung Treatment}

The process uses high-energy electromagnetic waves ( $x$-rays) to destroy CVOCs. Limited bench-scale experiments indicate that TCE and PCE dissolved in water are completely mineralized by this process. The mechanism for the oxidation of the organics in this process is believed to be related to the production of free radicals. Results from tests performed at Lawrence Livermore National Laboratory indicate an exponential decay of TCE in the aqueous and vapor phases as a function of radiation dose. For example a $100 \mathrm{kR}$ dose reduced a vapor phase concentration from $480 \mathrm{ppmv}$ to $177 \mathrm{ppmv}$ and a $300 \mathrm{kR}$ dose reduced the 
concentration to below 1 ppmv (Matthews, 1991). John Bayless of Pulse Sciences Inc. has recently completed a final report on the technology, available through the N.S.F. 1991 SBIR program.

The current principal investigators for this technology are Stephen Matthews of Lawrence Livermore National Laboratory and Donald T. Reed and James C. Cunnane of Argonne National Laboratory. John Bayless of Pulse Science Inc. is the industrial partner with Argonne National Laboratory.

\section{Electron Beam Technology}

Electron beams are used to produce highly reactive hydroxyl and superoxide radical species. This mechanism of this technology is similar to the photocatalytic and Bremsstrahlung processes described above, using water as the free radical forming catalyst. The technology has been demonstrated to be effective in aqueous solutions and is under development for wet vapor phase CVOC.s.

The principal investigator is Lou Rosocha of Los Alamos National Laboratory, and academic partners are University of Illinois, Florida International University and Auburn University.

Microwave-Induced Plasma Incineration

Microwave heating is used to create a uniform temperature distribution and generate reaclive species and destroy CVOCs. Argon is used as a carrier gas to eliminate the production of $\mathrm{NOx}$, and $\mathrm{O}_{2}$ is used as the oxygen source. To be practical, the process must be able to use air as the carrier gas. As a result, this project is currently in the research phase and is being funded by the Office of Technology Development.

The current principal irvestigators are Donald Reed and James Cunnane at Argonne National Laboratory.

Microwave Carbon Regenciation

Activated Carbon is used to strip CVOCs from air streams. Microwave energy in the frequency range of 0.9 to $4.5 \mathrm{GHz}$ converts the adsorbed CVOCs to carbon dioxide, water, and hydrochloric acid regenerating the carbon. Operating temperatures for this process are approximately $400^{\circ} \mathrm{C}$ and destruction efficiencies greater than $90 \%$ have been achieved (Varma and Nandi, 1991). One of the byproducts of this process in dry air is free chlorine, which is more difficult to remove from carbon than the other byproducts produced. T'o successfully regenerate carbon using this procedure it is necessary to convert this free chlorine to a more mobile species such as $\mathrm{HCl}$. This can be achieved by providing sufficient hydrogen to the waste stream (Varma and Nandi, 1991). This process is in the R\&D stage and has been funded by the Office of Technology Development.

The principal investigator is Ravi Varma of Los Alamos National Laboratory.

\section{Microwave Fluidized Bed Detoxification}

CVOC gas streams pass through a series of microwave heated actavated silicon carbide fluidized-bed reactors where they are converted to carbon dioxide and hydrochloric acid (Varma et al, 1990). Operating temperatures are about $600^{\circ} \mathrm{C}$ and conversion efficiencies of $98 \%$ have been achieved compared with $26 \%$ conversion by conventional thermal methods under similar operating conditions (Varma et al, 1990). The, process is in the research and development stage.

The principal investigator is Ravi Varma of Los Alamos National Laboratory.

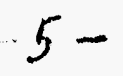


Tunable Hybrid Plasma

A gas-phase CVOC plasma is heated by electron beams and radio frequency power (c.g. microwaves) to create highly reactive hydroxyl and elemental oxygen radicals. These radicals are known to oxidize chlorinated organics such as TCE and PCE. The process is tunable because the amount of heating can be controlled by adjusting the microwave power. The process is relatively untested, and requires significant research and development.

Principal Investigator is Daniel Cohn of the Massachusetts Institutc of Technology. This technology will be tested under the Arid Site Integrated Demonstration.

\section{Vapor-phase Photolytic Destruction}

CVOCs undergo photolysis when exposed to the proper electromagnetic frequency corresponding to the intramolecular bonding energy of the CVOC. The electromagnetic energy in this process can be supplied by any source that emits within the absorption band of the target contaminant. TCE has an absorption band that centers around $230 \mathrm{~nm}$ while benzene has two relatively strong absorption bands at $184 \mathrm{~nm}$ and $202 \mathrm{~nm}$. Traditionally used sources have been mercury vapor lamps (Wekhof, 1991) which have a strong but relatively narrow banded output at $254 \mathrm{~nm}$. These sources were used in water treatment advanced oxidation processes with hydrogen peroxide or ozone, which have absorption bands in the vicinity of $254 \mathrm{~nm}$ leading to the formation of free radicals. The target contaminant would therefore be predominantly oxidized by the free radicals formed rather than by direct photolysis since the $254 \mathrm{~nm}$ line is on the fringe of the TCE absorption band. The oxidation of the contaminant in this situation would depend on its refractivity and the refractivity of its intermediate breakdown byproducts to free radical attack. In contrast, a broad band UV source would have the advantage of supplying energy in the absorption bands of several contaminants as well as their intermediate photolytic byproducts (Wekhof, 1991). This would ensure a complete mineralization of the contaminant by successive photolytic reactions.

Promising sources for broad band UV output are currently commercially available and custom built, pulsed xenon sources are becoming established technology. Bench scale tests of this technology have been successful in removing TCE, benzene, and polychlorinated biphenyl compounds (Wekhof, 1991).

The principal investigators are P. Daley and A. Boegel of Lawrence Livermore National Laboratory and Hann Hwang of Argonne National Laboratory. The industrial partner is PURUS, Incorporated. In addition, Alex Wekhof of Ultraviolet Energy Generators, Inc. has successfully completed bench scale tests on contaminated water, air, and soil.

\section{Concentrated Solar Energy}

This is a technology that uses concentrated solar energy to destroy TCE by UV photolysis. The technology has been applied to liquid-phase TCE and aqueous phase TCE in which oxidation is by direct photolysis and photocatalytic processes. The Solar Energy Research Institute (SERI) has been developing processes for detoxification of waste streams using solar energy. The processes have included photolytic/photocatalytic systems as well as solar thermal systems. The photolytic/photocatalytic system used an array of parabolic reflectors focused on a glass tube carrying the waste stream (Alpert et al, 1990). The thermal process involved solar-driven steam reforming performed in a solar furnace. The goal of both of these processes is a 99.99 to $99.9999 \%$ destruction efficiency at a few $\mathrm{kg} / \mathrm{hr}$. One disadvantage with these systems is that solar energy is not subject to operator control, although alternate energy sources can be used when solar is not available.

The principal investigator is B. Fupta of the Solar Energy Research Institute (SERI).

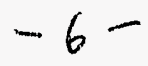




\section{Ultrasonic Decontamination}

Ultrasound is used to create free radicals either in a solution, or on a surface. The free radicals then oxidize the contaminant. Work with this technology has been done with aqueous and other solutions (Cheung et al., 1991; Koszalka et al., 1992) but much more experimentation is needed to determine the mechanistic pathways in the creation of free radicals using ultrasound.

This technology is being advanced by Duane P. Koszalka of Trinity Environmental Technologies, Inc.

Pulse Combustion

This process uses a two-stage thermal destruction method involving rapid fluid dynamic mixing in the combustion chamber and acoustic resonance to increase mass transport to the catalyst material (Keller et al., 19.90). The two stages a e high combustion intensity in the pulse combustor's combustion chamber and acoustic resonance in its tailpipe. Destruction efficiencies in excess of $99 \%$ have been achieved with methyl ethyl ketone in laboratory experiments.

The principal investigator is T. Tazwell Bramlette of Sandia National Laboratory.

\section{Adsorption-Molten Salt Oxidation}

This is a three step process involving activated carbon adsorption followed by regeneration using heated nitrogen to desorb the CVOCs. The CVOC laden nitrogen is then cooled, condensing the CVOCs to the liquid phase. The final step involves thermal destruction of the liquid CVOC in a molten salt bed at temperatures between 800 and $1050 \mathrm{C}$. The CVOC waste stream is completely mineralized in this process (Yosim et al., 1984).

\section{Zeolite Adsorption with Ozone Oxidation}

CVOCs are adsorbed to zeolite and then readily oxidized with ozone. This system has advantages of reduced fuel costs, but has the disadvantage of requiring ozone. The process is in the research and development stage.

The principal investigator is Jim Wilson of Oak Ridge National Laboratory. Vanderbilt University is an academic partner.

\section{'TECHNOLOGY PROGRAMMATIC REQUIREMENTS:}

The role of the technologies selected for Development, Testing and Evaluation (DT\&E) is to effectively abate CVOC emissions at reduced costs. The regulations promulgated pursuant to the Clean Air Act. of 1990 mandate maximum achicvable control technology for listed air toxics (some CVOCs). This should require air abatement systems to eliminate greater than 95 percent of the CVOC from an emission. To be economically competetive, emerging technologics should be capable of abating CVOC emissions at less than approximately $\$ 1$ per kilogram.

\section{TECHNOLOGY DEVELOPMENT AND EVALUATION REQUIREMENTS:}

\section{Cost Benefit}

The current target cost for destruction of CVOC air emissions is $\$ 1$ per kilogram (2.2 pounds). However, this number should be used with caution because there are several important considerations. For instance, if a relatively small amount of CVOC is to be removed, carbon adsorption may be the technology of choice 
because of low capital cost even though operating costs are about $\$ 10$ per kilogram of CVOC. If a catalytic system is used, the operating cost per kilogram would be about $\$ 1$ per kilogram. This is the current technology of choice for high concentrations of CVOC because the benefits of low operating costs outweigh the capital equipment costs and the installation cost (power resource, etc.). Therefore, to be cost competitive an emerging technology would have to have a process that would destroy significant amounts of CVOC for a prici of about $\$ 1$ per kilogram. Any reductions in capital equipment expenditures or operating costs over current technologies would also be extremely beneficial.

\section{Risk Reduction}

The greatest health and environmental risk associated with CVOC emissions is direct untreated discharges. This risk can be negligible, however, because of atmospheric dispersion and natural ultraviolet degradation by direct photolysis and photocatalytic processes. A significant level of risk reduction via the atmospheric exposure pathway is provided through adsorption onto activated carbon. However, if the activated carbon is disposed of at a landfill, this process has generated a secondary waste and a separate exposure pathway. If the activated carbon is regenerated, then there is minimal risk, as long as the desorbed material is destroyed. Catalytic oxidation and incineration provide direct destruction of the CVOC, so there is little risk from CVOCs. It is necessary to insure that the CVOC is completely mineralized in this process and that no products of incomplete oxidation that are dangerous are produced. In addition, hydrochloric acid is usually a secondary waste product from these processes and must be dealt with therein.

Schedule Acceleration

Because the air abatement technology is not the rate-limiting step towards achicving a ground water or soil remediation, we do not anticipate that an acceleration in the schedule will be achieved through improved air abatement technologies. However, treatment of vadose zone sources will reduce the time for groundwater cleanup.

\section{TECHNOLOGY INTEGRATION REQUIREMENTS}

\section{Regulatory Compliance}

Regulatory compliance will be achieved for the testing of the technologies under this program through formal approval with the State of South Carolina Department of Health and Environmental Control (SCDHEC). A detailed program plan containing a description of the technologies for testing, anticipated atmospheric discharges, and conditions for stop-testing has been sent to the SCDHEC in order to obtain an air permit.

\section{Societal Acceptance}

Societal acceptance of the technologies proposed for testing under this program is anticipated. The technologies are easily demonstrable and represent a solid commitment to sound environmental restoration. In addition, these technologies ultimately destroy the contaminants. This eliminates the problem of dealing with the waste in another form as is currently done with most adsorbent based remediation methods.

\section{Contribution}

The unique contribution envisioned for this technology development is a better and more cost effective method for treating VOC-laden emissions. Another contribution is that a single systematic effort is made towards testing the emerging technologies for air emissions control. As a result, industry will not have to complete repetitive research. Technologies will be comparatively tested and evaluated for technical performance and cost effectiveness. 


\section{Technology Transfer}

The projected technology transfer opportunities for a competitive technology under this program are enormous. Indeed, many of the systems to be demonstrated already have an industrial partner. Not only would the technology be applicable for remediation of ground water, but similar technology needs exist for many industrial processes that have similar discharges.

\section{TECHNOLOGY EVALUATION REQUIREMENTS}

All of the technologies selected for the first phase of testing under this program have the capability to meet the anticipated regulatory requirements with public acceptance. The lowest probability of success of the technologies is with the High-Energy Corona, because it has not been tested as completely as other technologies. The membrane separation technology is a suitable method for recovering CVOCs, but improvements must be made in the membranes for separating CVOCs. Because the technologies selected for DT\&E under this program have not been tested at the field scale, it is unknown whether they will be able to meet the current benchmark cost of $\$ 1$ per kilogram of CVOC abated. Thus it will be necessary as part of this program to evaluate the cost-effectiveness of technologies field-tested. 


\section{REFERENCES}

Adams, J.Q., and Clark, R.M., Evaluating the Costs of Packed-Tower Aeration and (3AC for Controlling Selected Organics, Journal AWWA, 83, No.1, 49-57, 1991.

Alpert, D.J., Sprung, J.L., Pacheco, J.E., Prairie, M.R., Reilly, H.E., Milne, T.A., and Nimlos, M.R., Sandia National Laboratories' Work in Solar Detoxification of Hazardous Wastes, SAND--90-(0935C DE90 016106, 1990.

Basta, N., The Recycling Loop Closes for Solvents, Chem. Eng., 98, No.12, 23-29, 1991.

Buck, F.A.M., and E.L. Seider, Commercial Vapor Treatment Processes, Paper Presented at Symposium on Soil Venting, Houston, TX, April 29 to May 1, 1991. (Paper may be obtained from King, Buck \& Associates, Inc., San Diego, CA)

Cheung, H. M., Bhatnagar, A., and Jansen, G., Sonochemical Destruction of Chlorinated Hydrocarbons in Dilute Aqueous Solution, Environmental Science and Technology, 25, 1510-1512, 1991.

Chozick, R., and Irvine, R.L., Preliminary Studies on the Granular Activated Carbon-Sequencing Batch Biofilm Reactor, Environmental Progress, 10, 282-289, 1991.

DeWaters, J.E., and DiGiano, F.A., The Influence of Ozonated Natural Organic Matter on the Biodegradation of a Micropollutant in a GAC Bed, Journal AWWA, 82, No.8, 69-75, 1990.

Fischer, A.M., Winterle, J.S., and Mill, T., Primary Photochemical Processes in Photolysis Mediated by Humic Substances, Photochemistry of Environmental Aquatic Systems, American Chemical Society, 1987.

Frost, A.C., Sawyer, J.E., Summers, J.C., Shah, Y.T., and Dassori, C.G., Kinetics and Transport Parameters for the Fixed-Bed Catalytic Incineration of Volatile Organic Compounds, Environmental Science and Technology, 25, 2065-2070, 1991.

Glaze, W.H., and Kang, J.W., Advanced Oxidation Processes. Description of a Kinetic Mode! for the Oyidation of Hazardous Materials in Aqueous Media with Ozone and Hydrogen Peroxide in a Semibatch Reactor, I\&EC Research, 288, 1573-1580, 1989a.

Glaze, W.H., and Kang, J.W., Advanced Oxidation Processes. Test of a Kinetic Model for the Oxidation of Organic Compounds with Ozone and Hydrogen Peroxide in a Semibatch Reactor, 1\&EC Rescarch, 28, 1580$1587,1989 \mathrm{~b}$.

Glaze, W.H., Kang, J.W., and Chapin, D.H., The Chemistry of Water Treatment Processes Involving Ozone, Hydrogen Peroxide and Ultraviolet Radiation, Ozone Science \& Engineering, 2, 335-352, 1987.

Herbert, K.J., Catalysts for Volatile Organic Compound Control in the 1990's; Paper presented at the 1990 Incineration Conference, San Diego, CA, May 14-18, 1990.

Keller, J.O., Gemmen, R.S., and Barr, P.K., Premixed Combustion in an Oscillating/Resonant Flow Field. Part I:Experimental Investigation, Proceedings of the 1990 ASME Winter Annual Meeting Nov. 25-30, 1990. Dallas. Tx.

Kittrell, J.R., Quinlan, C.W., and Eldridge, J.W, Direct Catalytic Oxidation of Halogenated Hydrocarbons, Journal of the Air and Waste Management Association, 41, 1129-1133, 1991.

Koffskey, W.E., Lykins, B.W., GAC Adsorption and Infrared Reactivation: A Case Study, Journal AWWA, 82, No.1, 48-56, 1990. 
Koszalka, D.P., Soodsma, J.F., and Bever, R.A., Ultrasonic Destruction of PCBs in Solids, Abstract from Symposium on Innovative Destruction Processes for Pollution Control, 1992.

Matthews, S. M., Environmental REmediation Using Intense Penetrating Bremsstraillung, Summary of work performed under TTP No. 1506-31, Aug. 8, 1991 .

Ollis, D.F., Pelizzetti, E, and Serpone, N., Photccatalyzed Deturuction of Water Contaminants, Environmental Scienses and Technolory, 25, 1522-1529, 1991.

Oxenford, J.L., and Lykins, E.W.Jr., Conference Summary: Pratical Adrects of the Design and Use of GAC, Lounal AWWA, 83. No.1, 58-64, 1991.

Palazzolo, M.A., Jamcochian, C.L., Stcinmctz, J.l., and L.ewis, D.t., Destruction of Chlorinatcd Hydrocarbons by Catalytic Oxidation, EPA/600/2-86/2072, 1986.

Rinko, J., and M. Traister, Practical Considerations for the Sclection of Pollution Control Equipment for VOC Emissions, Pyper presented at the 81 st Annual Air Pollution Control Association Mecting June 19.24, 1988, Dallas, TX. (Paper may be obtained from O'Brien \& Gere Engineers, lne., Syracuse, NY)

Servais, P., Billen, G., Ventresque, C., and Bablon, G.F., Microbial Activity in GAC Fi"ers at the Choisy-leRoi Trearment Plant, Lournal AWWA, 23, No.2, 62-68, 1991.

Speth, T.F and Miltner, RJ., Technical Note: Adsorption Capacity of GAC Ior Synthetic Organics, Journal AWWA, 83, No.2 72.75, 1990 .

Steverson, E,M., Provoking a Firestorm: Waste incineration, Environmenial Science und Teshnolon, 25, $1808 \cdot 1814,1991$.

Strandberg, G.W., Donaldson, T.L., and Farr, L.L., Degradation of Trichlornethylene and trans-12. Dichloroethylene by a Methanotrophic Conscrtium in a Fixed-Film, Packed-Bed Rini eactor, Environmental Scierse and Technology, 23, 1422-1425, 1989.

Takacs, $L_{\text {., }}$ and Moilanen, G. L., Simultaneous control of PCDD/PCUF, $\mathrm{HCl}$ and $\mathrm{NO}_{\mathrm{k}}$ ernissions from municipal solid waste incinerators with Ammoniz injection (1991). Journal of Air and Waste Maragement Assoctation, 41, 716.722.

Varma, R., Nandi, S.P., and Cleaveland, D.C., Microwave-Assisted Chemical Process for Treatment of Hazardous Waste, DOE/HWP-"28.ANL-87.22, 1987.

Vurma, R., Nandi, S.P., and Katz, J.D., Detoxification of Hazardous Waste Streams Using Micrownave-

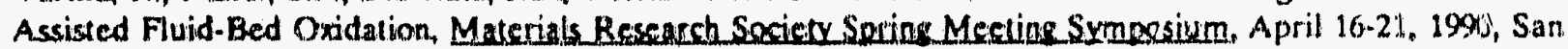
Francisco, $C A$.

Varma, $R_{n}$, and Nandi, S.P., Oxidative Degradation of Trichloroethylene Adsorbed on Active Cartwans: Use of Microwave Energy, LA.UB--21-1552.0E21 01,3656, 1991.

Vancil, M.A., Howle, K.H., Herndom, D.J., and Shaseef, S.A., Air Stripping of Contaminated Watier Sources - Air Emissions and Controls, EPA-450/3-87-012, 1987.

Yosim, SJ., Kelloge L.G., and Sudar, S., Mohten Salt Destruction of HCB and Chlordane- Bench and Pilor Senle Tests. Find Report EPA/600/284/148. 
Wekhof, A., Treatment of Contaminated Water, Air and Soil With UV Flashlamps, Environmental Progress, 10, 241-247, 1991.

Wijmans, J.G., Kaschemekat, J., Davidson, J.E., and Baker, R.W., Treatment of Organic-Contaminated Wastewater Streams by Pervaporation, Environinental Progress, 2, No.4, 262-268.

Zafiriou, O.C., Marine Organic Photochemistry Previewed, Marine Chemistry, 5, 497-522, (1977). 

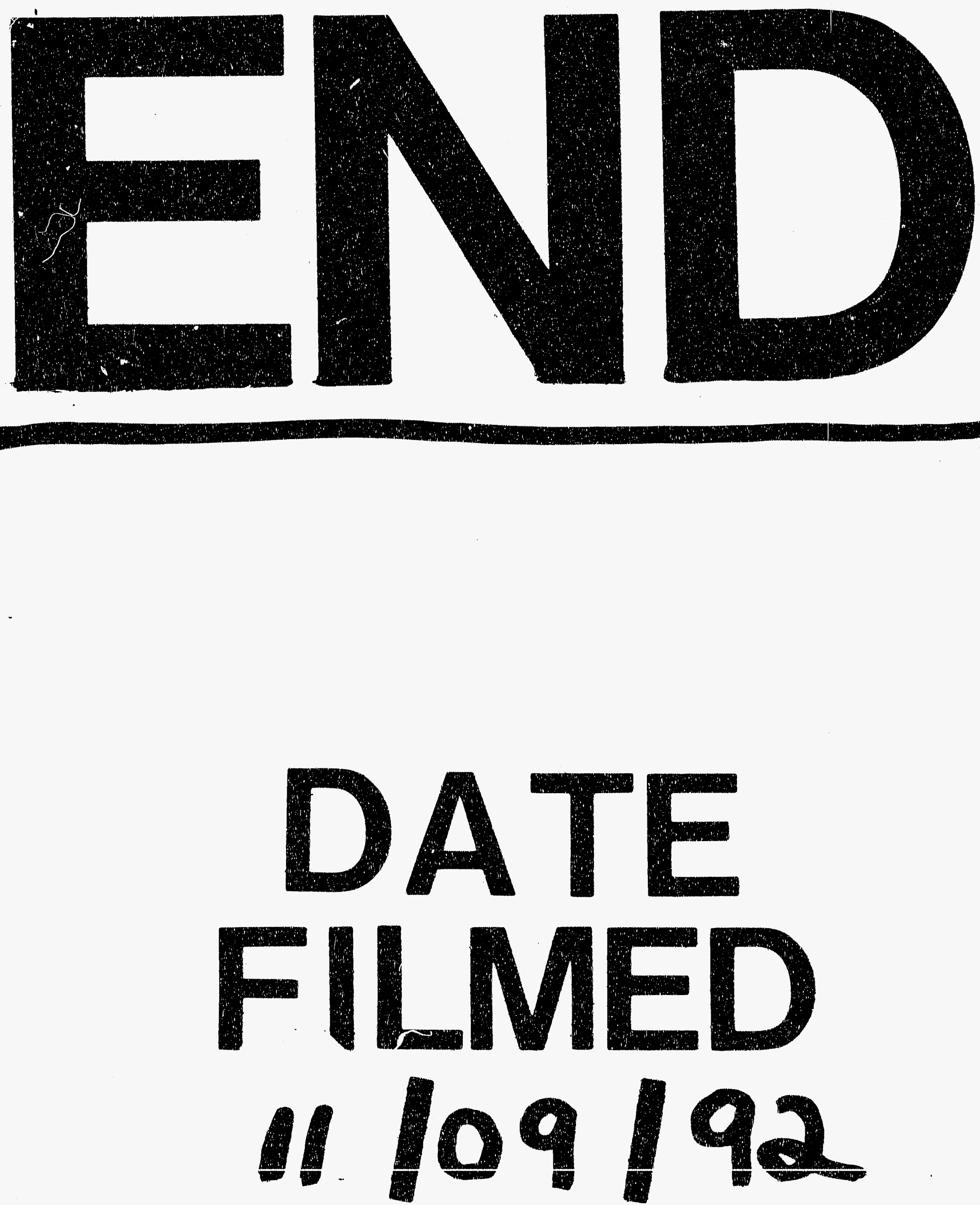


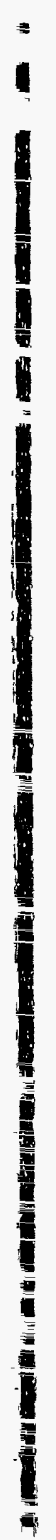

